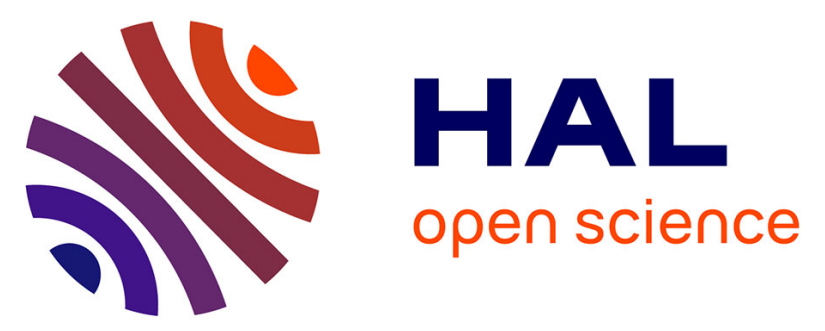

\title{
High-power passively mode-locked dissipative soliton fiber laser featuring cladding-pumped non-CVD thulium-doped fiber
}

Dmitry Gaponov, Romain Dauliat, Dia Darwich, Tigran Mansuryan, Raphaël Jamier, S Grimm, K Schuster, Philippe Roy

\section{To cite this version:}

Dmitry Gaponov, Romain Dauliat, Dia Darwich, Tigran Mansuryan, Raphaël Jamier, et al.. High-power passively mode-locked dissipative soliton fiber laser featuring cladding-pumped nonCVD thulium-doped fiber. Journal of the Optical Society of America B, 2015, 32 (8), pp.1656. 10.1364/JOSAB.32.001656 . hal-01250320

\section{HAL Id: hal-01250320 https://hal.science/hal-01250320}

Submitted on 6 Jan 2016

HAL is a multi-disciplinary open access archive for the deposit and dissemination of scientific research documents, whether they are published or not. The documents may come from teaching and research institutions in France or abroad, or from public or private research centers.
L'archive ouverte pluridisciplinaire HAL, est destinée au dépôt et à la diffusion de documents scientifiques de niveau recherche, publiés ou non, émanant des établissements d'enseignement et de recherche français ou étrangers, des laboratoires publics ou privés. 


\title{
High power passively mode-locked dissipative soliton fiber laser featuring cladding pumped non-CVD-thulium doped fiber
}

\author{
D. A. Gaponov ${ }^{1, *}$ R. Dauliat ${ }^{1}$, D.Darwich ${ }^{1}$, T. Mansuryan ${ }^{1}$, R. Jamier ${ }^{1}$, S. Grimm ${ }^{2}$, K. Schuster ${ }^{2}$, and P. \\ Roy $^{1}$ \\ ${ }^{1}$ Xlim UMR CNRS-Université de Limoges n7252, 123 Av. Albert Thomas 87060 Limoges, France \\ ${ }^{2}$ Institute of Photonic Technology, Albert Einstein Straße 9, 07745 Jena, Germany \\ *Corresponding author: d.gaponov@novae-laser.com ${ }^{* *}$
}

Received Month X, XXXX; revised Month X, XXXX; accepted Month X,

XXXX; posted Month X, XXXX (Doc. ID XXXXX); published Month X, XXXX

\begin{abstract}
The characterization of a thulium-doped fiber made from the new powder technology in the mode-locking regime is reported. High average output power of $185 \mathrm{~mW}$ at a repetition rate of $9 \mathrm{MHz}$ was achieved directly from the oscillator, which is resulting in $21 \mathrm{~nJ}$ of pulse energy. The single-pulse operation regime was confirmed by careful numerical modeling of the laser cavity.

OCIS Codes: (060.2320) Fiber optics amplifiers and oscillators; (140.3510) Lasers, fiber; (140.4050) Mode-locked

lasers

http://dx.doi/org/10.1364/AO.99.099999
\end{abstract}

\section{Introduction}

Owing to considerable recent progress in different fields of science and technology, high power ultrafast laser sources emitting around $2 \mu$ mwavelength range attract an increasing attention. In this context, fiber based systems have assert their strengths/potential due to noticeable compactness and robustness, while state-of-the-art results in term of absolute values are still lower compared to those obtained from ytterbium doped fiber sources.

Various amplification techniques could be used to achieve either high energy or high peak power at this wavelength. Recently, $100 \mathrm{~kW}$ in peak powerwas obtained [1] with CPA \& gainswitched (ns) seed pulse. In turn, mode-locked seed oscillator used in MOPA scheme allowsreaching $\mu \mathrm{J}$-level in pulse energy with sub-ps pulses[2,3]. Moreover, impressive results wererecently demonstrated with CPA systems based on Tmdoped rod-type fibers. Sub-ps pulses were amplified to reach $152 \mathrm{~W}$ in average power and $4 \mathrm{MW}$ in peak power [4].

To achieve a high average power directly at the output ofthe ultrafast oscillator,one must provide effective stretching of the pulse inside the cavity during its round-trip. One of the regimes in whichthis could be realized, is theso-called dissipative solitonic (DS) regime which demands netnormal cavity dispersion. Furthermore, it has been shown that the energy scaling is directly related with absolute value of normal dispersion $[5,6]$. In contrastto the case of $\mathrm{Yb}$-doped sources, where afiber chromatic dispersion is naturally normal for $\lambda>1.5 \mu \mathrm{m}$, one must use dispersion compensating elements (either bulk, or specialty fiber based) inside the cavity to provide such an operating regimeat 2 $\mu \mathrm{m}$ [7]. Typically, pulse energy measured directly at the output of a passively mode-locked thulium fiber oscillators in net normal dispersion cavities is in order of few $\mathrm{mW}$ [8]. Recently, a hundreds-mw average output power level was demonstrated exploiting high-order solitonic concept[9], where even few

Currently works in NOVAE SAS, Limoges, France nanojoules pulses providedup to $21 \mathrm{~kW}$ in peak powerdue to their sub-ps nature.

In this paper we demonstrated the generation of high average power $(185 \mathrm{~mW})$ andhigh energy $(21 \mathrm{~nJ})$ picosecond pulsesin thenet normal dispersion cavity based on thecladding-pumped Tm-doped fiber fabricated using one of the newest glass manufacturing technologies.This process, called "Repusil", consisting in the synthesis of doped optical glass by sintering and vitrification of silica powders.Repusil-based fibers havealready demonstrated remarkable capabilities for the fabrication of efficient and homogeneous active materials [10], rendering them relevant competitors to existing methods of fiber fabrication.Obtained performances in terms of average and peak powers directly at the oscillator output are not the record ones at this wavelength range; however, to the best of our knowledge, they are the highest in terms of average power and pulse energy directly at the output of the thulium modelocked fiber lasers with a net normal dispersion cavity.

\section{Fiber preparation and characterization in continuous wave (CW)regime}

The material processing for the fabrication of doped silica is based on the REPUSIL process and described in [11]. The active material is made starting from pure silica particles which are doped in an aqueous dispersion with rare earth precursor (0.81weight $\% \mathrm{Tm}^{3+}$ with ratio $\mathrm{Al}^{3+}: \mathrm{Tm}^{3+}=6: 1$ ). This synthesis technology allows high batch to batch reproducibility and thesilica rodsshow a high homogeneity: low radial (see Fig 1.a) and longitudinal variation of a refractive index:2.10 ${ }^{-4}$. It is worth to note that with obtained performances this Repusil technology could be especially useful in fabrication of large cores/volumes and overpasses the limitation of traditional MCVD process on the ability to accurately control the refractive index profile. 
The fabricated fiber has a core diameter equal to $8 \mu \mathrm{m}$, an $\mathrm{D}^{-}$ shaped outer cladding of $122 \times 146 \mu \mathrm{m}$, and is coated with a low index polymer (NA 0.35) providing an efficient cladding pumping. Itsrefractive index profile is presented in the Figure 1. The $\mathrm{V}$ number is estimated to be 2.36 at $\lambda=1900 \mathrm{~nm}$ which confirms that the fiber is truly singlemode in the working region (a near-field image of the fundamental mode at $\lambda=1960$ is shown in the inset to Fig.1b).The measured cladding absorption reaches $5 \mathrm{~dB} / \mathrm{m}$ at $\lambda=790 \mathrm{~nm}$ while the background losses were estimated to be $0.1 \mathrm{~dB} / \mathrm{m}$ at $\lambda=930 \mathrm{~nm}$ and $0.5 \mathrm{~dB} / \mathrm{m}$ at $\lambda=1335 \mathrm{~nm}$. It should be noted that the level of grey losses are quite high, compared to MCVD-based fibers, but dissipative solitonic cavity could tolerate them and is an ideal candidate for such a fiber to be implemented in. The performance of the fabricated fiber was tested in a continuous wave regime in a simple $4 \%-99 \%$ laser cavity, giving $43 \%$ of slope efficiency with $5 \mathrm{~m}$ long sample.
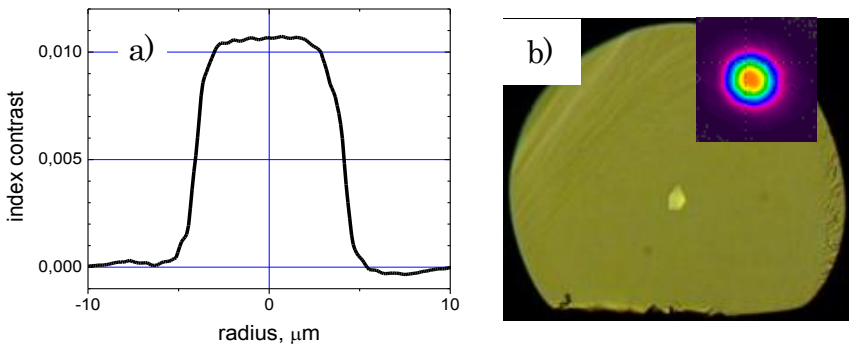

Fig. 1.a) the refractive profile of the fabricated powder thulium-doped fiber, b) corresponding fiber cross-sectionmicroscope image, inset - a near-field image of the fundamental mode at $\lambda=1960 \mathrm{~nm}$.

\section{Experimental set-up}

Our oscillator, shown in Figure 2, is based on a Fabry-Perot cavity. To operate in a net normal cavity regime, the dispersion compensation (DC) has been achieved with the help of a commercially available OFS80 fiber, the chromatic dispersion of which is calculated to be $+0.0489 \mathrm{ps}^{2} / \mathrm{m}$ at $\lambda=1960 \mathrm{~nm}$. A small piece of single-mode fiber (SMF-28) has been put in between the Tm-doped fiber and the DC fiber in order to facilitate the splicing and a control of the total cavity dispersion. To evacuate the unabsorbed pump, the end of the active fiber was placed in a high-index polymer. The cavity has been passively mode-locked using a commercially available Saturable Absorber (BATOPSAM-1960-54). The length of the active Tm-doped fiber (TDF) has been optimized to fit the working wavelength of SA mirror $(\mathrm{SAM}) \lambda=1960 \mathrm{~nm}$ and estimated to be $\sim 2 \mathrm{~m}$.

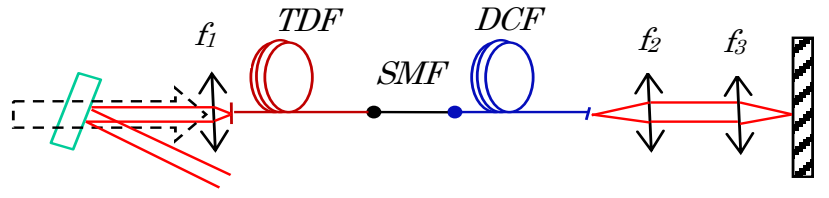

Fig. 2. Principal scheme of the oscillator:TDF - active thulium-doped fiber under test, SMF - transition single-mode fiber (SMF28), DCF dispersion compensating (OFS80) fiber.

This fiber length still provided efficient laser operation, which was confirmed by the cut-back slope efficiency measurements drop of only few percents compared to $5 \mathrm{~m}$ active fiber sample was observed.The fiber is cladding pumped with a multimode diode operating at $\lambda=793 \mathrm{~nm}$ from free-space using a couple of $f_{1}=8 \mathrm{~mm}$ lenses. The free $0^{\circ}$ cleaved fiber-facet acts as output

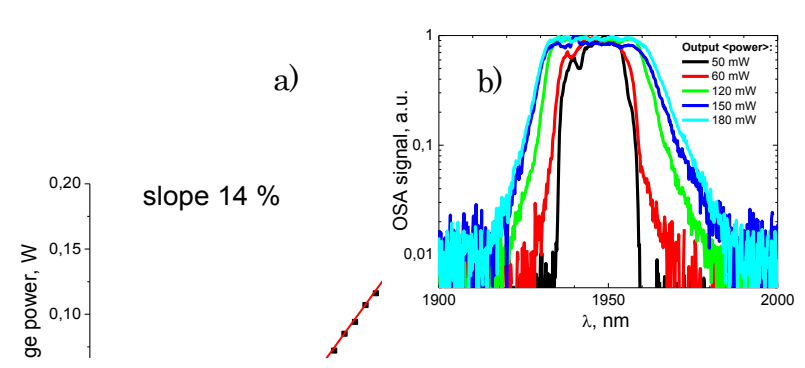

Fig. 3. a) Oscillator efficiency and output average power versusthe launched pump power; inset - pulse train, b) spectral evolution with respect to the output average power in the monopulse regime.

coupler. A careful alignment of the focalization on SAMwith the pair of $f_{2,3}=8 \mathrm{~mm}$ lenses enables a stable self-starting modelocking.

\section{Experimental results}

Up to $185 \mathrm{~mW}\left(f=9 \mathrm{MHz}, \mathrm{E}_{\mathrm{p}} \sim 21 \mathrm{~nJ}\right)$ of average power was obtained at the output of the oscillator in the single-pulse regime (see fig. 3a). Further increase of the pump power led to the doubled or even tripled pulse operation with respect to the fundamental frequency. We address this issue to the excessive energy fluence incident on SAM. Spectrums at different output average powers are presented in figure $3 \mathrm{~b}$. The full width at half maximum (FWHM) varied from $16.6 \mathrm{~nm}$ up to $34 \mathrm{~nm}$ at maximum signal power level.

The temporal characterizationwith 85 ps range autocorrelator (Femtochrome FR-103-XL) showed no additional replicas when pump power lies in the single-pulse region (up to $185 \mathrm{~mW}$ ) (see Fig. 4). A typical autocorrelation trace for the output power $\mathrm{Ps}_{\mathrm{S}}=50 \mathrm{~mW}\left(\mathrm{E}_{\mathrm{p}} \sim 5.6 \mathrm{~nJ}\right)$, which lies in the beginning of the monopulse region, is presented in Fig. 3a. The autocorrelation FWHM (corresponding spectrum FWHM = $16.6 \mathrm{~nm}$ ) was measured to be $24.4 \mathrm{ps}$ which gives $15.8 \mathrm{ps}$ of pulse duration (supposing sech²pulse shape).

\section{Pulse compression experiment}

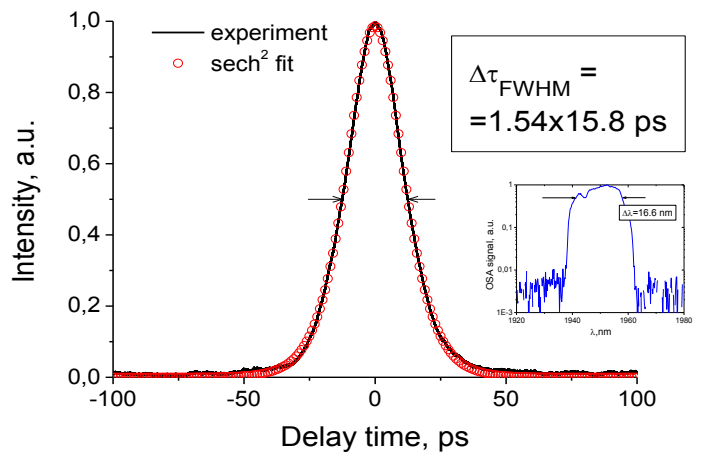

Fig. 4. The autocorrelation trace and corresponding spectrum (in the inset) at the output average power $\mathrm{Ps}_{\mathrm{s}}=50 \mathrm{~mW}$

Afterwards, a pulse compression experiment was conducted using a pair of $600 \mathrm{l} / \mathrm{mm}$ diffraction gratingswith a blaze wavelength of $1.6 \mu \mathrm{m}$. However, at $\lambda=1.95 \mu \mathrm{m}$ these gratings become efficient only for one polarization with diffraction 
efficiency of 90\%. Therefore a Glanpolarizer and two half-wave plates were used to maximize a) the average power of the pulse in the compressor andb) the signal in the autocorrelator (AC) (see Fig.5). It is worth to note that the polarizer also acts as the optical isolator preventing fromthe parasitic back reflections to the oscillator cavity thatcould easily disturb the mode-locking regime.Due to the mentioned limitations the overall compression efficiency in this configuration was not exceeding $33 \%$.

At the maximum output average power, however, the Glan polarizer did not provide a high optical isolation and the modelocking regime was disturbed after few minutes of operation. Therefore the average output power providing unperturbed regime was fixed to be $100 \mathrm{~mW}\left(\mathrm{E}_{\mathrm{p}}=11 \mathrm{~nJ}\right)$ that gave an output pulse spectrum FWHM of $22.6 \mathrm{~nm}$ (see Fig. 6a). The corresponding autocorrelation traces for the pulse before and after compression are presented in Fig.6 (b and c, respectively). The $11.5 \mathrm{ps}$ pulse was compressed down to $1.9 \mathrm{ps}$ (assuming $\mathrm{sech}^{2}$ profile, $\mathrm{P}_{\text {peak }}=1.9 \mathrm{~kW}$ ).A time-bandwidth product for the compressed pulse is equal to 2 that is approximately 2.5 times higher than typical values $(\sim 0.8)$ for dissipative solitonic regime.

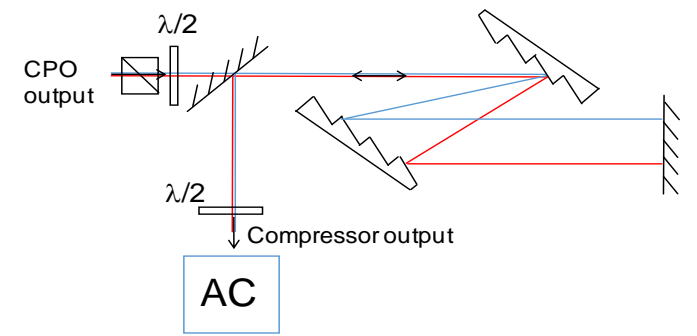

Fig.5. Pulse compression set-up. AC-autocorrelator. a)

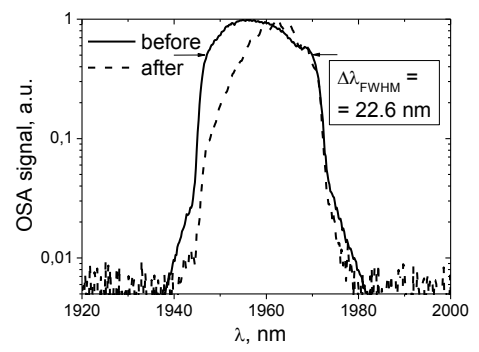

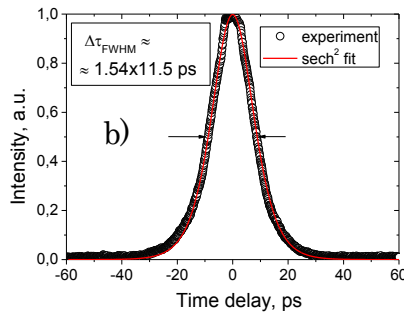

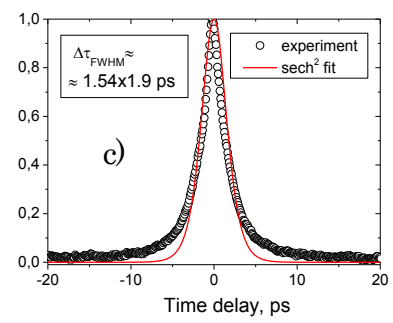

Fig.6.Compression experiment: spectrums and autocorrelation tracesof the pulse before (a-solid line, b) and after(a-dashed line, ckompression.In Fig. 6b,c the solid red line represents sech2fit to the experimental data.

This could be explained by not optimal alignment of diffraction gratings in our set-up (one could see a slight cut of the short wavelengths components in compressed pulse spectrum, Fig 6a). One could mention also, that more efficient gratings (etc, working in transmission, polarization independent) together with a better compressor alignment immediately allows to reach $10 \mathrm{~kW}$ peak power level in this system.

\section{Numerical modeling}

To confirm the monopulse operation, a numerical modeling was made with the help of a commercially available software [12] based on the split step Fourier method. The schemeused in the calculations is illustrated in Fig. 7. The elements lengths $(\mathrm{L})$ were taken to fit the experimental cavity: LTDF $=1.9 \mathrm{~m}$, LoFS $80=7 \mathrm{~m}$, $\mathrm{LSMF}_{28}=2.1 \mathrm{~m}$, Lfree-space $=0.4 \mathrm{~m}$ ). The SAM parameters were chosen respecting the datasheet: a relaxation time of $\tau=10 \mathrm{ps}$ and a modulation depth of $\Delta \mathrm{R}=30 \%$. The dispersion parameter of SMF28 fiber is known to be $\beta_{2, \mathrm{SMF}}=-0.0679 \mathrm{ps}^{2} / \mathrm{m}$ at $1.9 \mu \mathrm{m}$ [8],

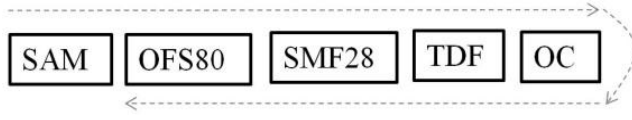

Fig.7.Configuration of the element blocks used in the numerical modeling of the experimental cavity from Fig.2. Dashed lines with arrows illustrate cavity round trip. $\mathrm{OC}$ - output coupler element

which corresponds to $-0.0778 \mathrm{ps}^{2} / \mathrm{m}$ at $1.96 \mu \mathrm{m}$. For TDF the dispersion was estimated to be $\beta_{2, \mathrm{TDF}}=-0.07875 \mathrm{ps}^{2} / \mathrm{m}$ at $1.96 \mu \mathrm{m}$. Thus the cavity has a moderate level of the net normal dispersion $\beta_{2, \text { net }}=+0.0586 \mathrm{ps}^{2}$. The Fresnel $4 \%$ reflection at the fiber endfacet provided the positive feedback in the laser cavity. The gain FWHM was measured to be $\Delta \lambda=160 \mathrm{~nm}$ and assumed to have a Gaussian shape .
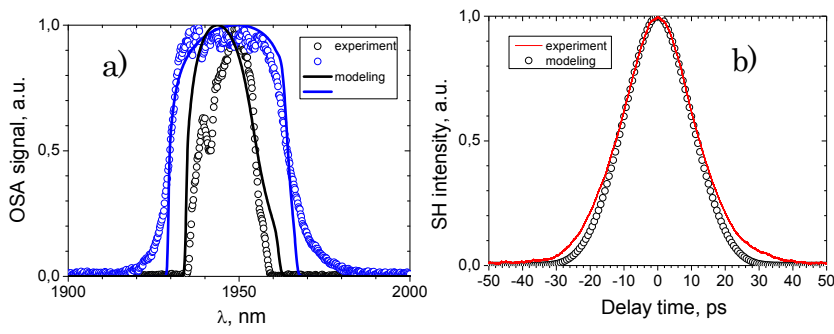

Fig.8.Experimental (open circles) and corresponded calculated (solid lines) of a) spectra and b) autocorrelation traces for monopulse $\mathrm{ML}$ regime. a) Black color for lower and Blue color for upper $\mathrm{ML}$ thresholds, respectively, $b$ ) for lower ML threshold

The modelling process initiated by the "quantum-noise" allowed us to identify the region of the monopulse operation of the oscillator. This is illustrated in Fig.8where a comparison between the experimental and theoretical spectra as well as the corresponding autocorrelation traces are presented for minimum and maximum pump power providing monopulse operation. It is worth to note that the spectral \&temporalcharacteristics in this range are matching quite well with that observed in the experiment. The gain saturation energy $\mathrm{E}_{\text {sat }}$ was varied in the range between 0.1 and $0.4 \mathrm{~nJ}$. With further increasing of $\mathrm{E}_{\text {sat }}$ (which is, in turn, proportional to the pump power) converging to the stable solution was not possible.

\section{Conclusion}

In conclusion, we presenteda detailed characterization of afiber made from anovel powder technology in the mode-locking regime 
initiated by a commercially available saturable absorber. The stable self-starting operationregime could be preserved during hours when proper alignment is achieved. In terms of performance we demonstrated up to the $185 \mathrm{~mW}$ of average power ( $14 \%$ slope efficiency, pulse energy $\mathrm{E}_{\mathrm{p}}=21 \mathrm{~nJ}$ ) insingle pulsed regime, confirmed by the theoretical modelling of the cavity. However, an improper isolation at the laser output allows the hours-long operation of the laser at the power level less than $100 \mathrm{~mW}$ only and pure single-pulse regime in not stable region, still needs to be confirmed experimentally in stabilized system.Precise measurements of the pulse duration were done at $50 \mathrm{~mW}$ of output average power $\left(\mathrm{E}_{\mathrm{p}}=5.6 \mathrm{~nJ}\right)$ for uncompressed pulsesin the beginning of the single-pulse regime region and at $100 \mathrm{~mW}\left(\mathrm{E}_{\mathrm{p}}=11 \mathrm{~nJ}\right)$ of average powerduring the compression experiment. The 11.5 ps pulseswere compressed down to 1.9 pscorresponding to a peak power $\mathrm{P}_{\text {peak }}=1.9 \mathrm{~kW}$. The bulk compression scheme did not allow increasing the peak power in compressed pulse due to the low optical efficiency of diffraction gratingsavailable in the experiment.

The presented results confirmthe interest of such kind of fibers to be implemented in potentially all-fiber schemes for operation in mode-locking regimes. Moreover, relatively high $(185 \mathrm{~mW})$ average power output directly at the output of the oscillator was demonstrated at wavelength of $1.96 \mu \mathrm{m}$.

\section{Acknowledgments}

Authors are gratefully acknowledging the Région Limousin (France) to support this work in frame of AVANTAGE project through European Union FEDER program.

\section{References}

[1] A. M. Heidt, Z. Li, J. Sahu, P. C. Shardlow, M. Becker, M. Rothhardt, M. Ibsen, R. Phelan, B. Kelly, S. U. Alam, and D. J. Richardson, "100 kW peak power picosecond thulium-doped fiber amplifier system seeded by a gain-switched diode laser at $2 \mu \mathrm{m}, "$ Opt. Lett. 38, 1615-1617 (2013)

[2]R. A. Sims, P. Kadwani, A. Sincore, L. Shah, Martin Richardson, "1 $\mu \mathrm{J}$, sub-500 fs chirped pulse amplification in a Tm-doped fiber system," Opt. Lett. 38, 121-123 (2013)

[3]Peng Wan, Lih-Mei Yang, and Jian Liu, "High power $2 \mu \mathrm{m}$ femtosecond fiber laser," Opt. Express 21, 21374-21379 (2013)

[4] Fabian Stutzki, Christian Gaida, Martin Gebhardt, Florian Jansen, Andreas Wienke, Uwe Zeitner, Frank Fuchs, Cesar Jauregui, Dieter Wandt, Dietmar Kracht, Jens Limpert, and Andreas Tünnermann, "152W average power Tm-doped fiber CPA system," Opt. Lett. 39, 4671-4674 (2014)

[5] W. H. Renninger, A. Chong, and F. Wise, "Dissipative solitons in normal-dispersion fiber lasers", Phys. Rev. A 77, 023814 (2008) [6] Nail Akhmediev, Adrian Ankiewicz, José-María Soto-Crespo, and Philippe Grelu, "Dissipative solitons: Present Understanding, Applications and New Developments" I. J. Bifurcation and Chaos19(8):2621-2636 (2009)

[7]A. Cabasse, B. Ortaç, G. Martel, A. Hideur, and J. Limpert, "Dissipative solitons in a passively mode-locked Er-doped fiber with strong normal dispersion," Opt. Express 16, 19322-19329 (2008)

[8] A. Wienke, F. Haxsen, D. Wandt, U. Morgner, J. Neumann, D. Kracht, "Ultrafast, stretched-pulse thulium-doped fiber laser with a fiber-based dispersion management," Opt. Lett. 37, 24662468 (2012)

[9]M.A. Chernysheva, A.A. Krylov, M. Chengbo, R.N. Arif, A.G. Rozhin, M.H. Rummelli, S.K. Turitsyn, E.M. Dianov, "HigherOrder Soliton Generation in Hybrid Mode-Locked ThuliumDoped Fiber Ring Laser," Selected Topics in Quantum Electronics, IEEE Journal of, vol. 20, 1100908 (2014)

[10] M. Leich, F. Just, A. Langner, M. Such, G. Schötz, T. Eschrich, S. Grimm, "Highly efficient Yb-doped silica fibers prepared by powder sinter technology," Opt. Lett. 36, 1557-1559 (2011)

[11] K. Schuster, S. Unger, C. Aichele, F. Lindner, S. Grimm, D. Litzkendorf, J. Kobelke, J. Bierlich, K. Wondraczek, H. Bartelt, "Material and technology trends in fiber optics", Advanced Optical Technologies 3(4),447 - 468, 2014

[12] http://www.fiberdesk.com. 